RESEARCH PAPER

\title{
The economic burden of smoking in California
}

\author{
W Max, D P Rice, H-Y Sung, X Zhang, L Miller
}

Tobacco Control 2004;13:264-267. doi: 10.1136/tc.2003.006023

See end of article for authors' affiliations

......

Correspondence to: Professor Wendy Max, Institute for Health \& Aging, University of California, San Francisco, 3333 California Street, Suite 340, San Francisco CA 94118, USA; wmax@ itsa.ucsf.edu

Received

5 September 2003

Accepted 15 March 2004

\begin{abstract}
Objective: To develop estimates of the direct and indirect costs of smoking for California in 1999.
Methods: A prevalence based approach was used to estimate the annual costs of smoking. Econometric models were used to estimate the smoking attributable fraction (SAF) for direct costs (hospitalisations, ambulatory care, prescription drugs, home health care, and nursing home services) and indirect costs due to lost productivity from smoking related illness. The models controlled for socioeconomic factors and other risk behaviours. Epidemiological methods were used to estimate the SAF for indirect costs due to lost productivity from premature deaths. The SAFs were applied to total health care expenditures, days lost, and deaths to obtain smoking attributable total costs.

Results: In 1999, the total costs of smoking in California were $\$ 15.9$ billion, $\$ 475$ per resident, and $\$ 3331$ per smoker. Direct costs were $\$ 8.6$ billion (54\% of the total), indirect costs due to lost productivity from illness were $\$ 1.5$ billion $(10 \%)$, and indirect costs due to premature deaths were $\$ 5.7$ billion (36\%). The cost of smoking was $\$ 9.4$ billion for men and $\$ 6.3$ billion for women. There were 43137 deaths attributed to smoking, representing a total of 535000 years of life lost. The value of life lost per death averaged $\$ 132000$, or 12.4 years.

Conclusions: California smoking related costs are high. The cost methodology presented is useful for other states and nations interested in estimating their costs of smoking. Cost estimates can be used to evaluate the level of cigarette taxes and other policies related to smoking.
\end{abstract}

who may continue to experience the adverse health effects of smoking. Table $\mathrm{l}$ also contains the smoking attributable fractions (SAFs) for direct costs and indirect costs by sex. Except for the indirect costs of lost productivity due to smoking related illness, the SAFs are substantially smaller for women than for men-11.4\% of direct costs for men and $8.0 \%$ for women are attributable to smoking. Smoking accounts for $22.2 \%$ of deaths for men and $15.8 \%$ for women.

\section{Total costs}

The total costs to California of the health effects of smoking in 1999 amounted to $\$ 15.8$ billion, equalling $\$ 475$ per resident and $\$ 3331$ per smoker (table 2). The direct costs represented $54 \%$ of the total, indirect lost productivity due to illness was $10 \%$, and indirect lost productivity due to premature death was $36 \%$.

The cost of smoking for men was $\$ 9.4$ billion compared to $\$ 6.3$ billion for women. However, the comparison differs by type of cost. Women have similar direct health care costs as men. While fewer women smoke, women tend to be heavier users of the health care system in general and they tend to live longer than men. Men and women had nearly equal lost productivity from illness; men had higher earnings, but women missed more days from work on average. Lost productivity from premature death was 3.5 times as great for men as for women because more men die of smoking related illness and men are paid more in the labour market and thus have greater lost earnings. On a per resident basis, the total cost for men was almost 50\% higher than for women; on a per smoker basis, costs for men were only $6 \%$ higher.

\section{Direct costs}

Direct costs were $\$ 8.6$ billion, with almost half of these costs (47\%) going for hospital care, $24 \%$ for ambulatory care, $15 \%$

Abbreviations: CDC, Centers for Disease Control and Prevention; SAF, smoking attributable fraction 


\begin{tabular}{|c|c|c|c|}
\hline & Total & Men & Women \\
\hline Population ('000) & 24222 & 12000 & 12222 \\
\hline \multicolumn{4}{|l|}{ Smoking prevalence: } \\
\hline Current smokers (\%) & 18.7 & 22.1 & 15.3 \\
\hline Former smokers (\%) & 25.8 & 28.9 & 22.8 \\
\hline \multicolumn{4}{|c|}{ Smoking attributable fractions (\%): } \\
\hline Direct cost & 9.3 & 11.4 & 8.0 \\
\hline Ambulatory & 5.2 & 7.1 & 4.1 \\
\hline Prescriptions & 10.0 & 13.0 & 8.3 \\
\hline Hospital & 12.0 & 13.6 & 10.6 \\
\hline Home health & 4.5 & 6.1 & 4.0 \\
\hline Nursing home & 23.0 & 25.4 & 21.8 \\
\hline \multicolumn{4}{|l|}{ Indirect lost productivity } \\
\hline Work loss days & NA & 8.0 & 8.9 \\
\hline Bed disability days & NA & NA & 15.5 \\
\hline Premature deaths & NA & 22.2 & 15.8 \\
\hline
\end{tabular}

for nursing home care, $13 \%$ for prescriptions, and $1 \%$ for home health services. Smoking attributable costs for men exceeded those for women for hospitalizations and ambulatory care, while costs for women were greater than those for men for nursing home care, prescriptions, and home health care.

\section{Lost productivity due to illness and premature death}

Productivity losses due to smoking related illness in California amounted to $\$ 1.5$ billion in 1999 , indicating that smokers lost many days from productive activities. Losses amounted to \$276 per male smoker and \$381 per female smoker.

There were 43137 deaths attributed to smoking, accounting for $18.9 \%$ of all deaths in California in 1999. The value of lost productivity from smoking related deaths in 1999 dollars was $\$ 5.7$ billion. The value of life lost per death averaged $\$ 132$ 000; total years of life lost amounted to 535000 years or 12.4 years of potential life lost per death.

The leading cause of smoking attributable death was cardiovascular disease, accounting for 17137 premature deaths. There were 14290 and 11290 deaths due to neoplasms and respiratory diseases, respectively. Non-smokers also died as a result of smoking in California, including infants exposed in utero ( 68 deaths), deaths related to fires caused by cigarettes (64 deaths), and non-smokers exposed to environmental tobacco smoke (4560 deaths). ${ }^{26}$

\section{DISCUSSION}

California has one of the most comprehensive tobacco control programmes in the nation, and the prevalence of smoking has been declining over time. Nonetheless, the health effects

Table 2 Cost of smoking by type of cost and sex, California, 1999

\begin{tabular}{|c|c|c|c|c|}
\hline Type of cost and sex & Amount ('000s) & Distribution (\%) & Per resident & Per smoker \\
\hline Total & $\$ 15759779$ & 100.0 & $\$ 475$ & $\$ 3331$ \\
\hline Direct cost & $\$ 8564623$ & 54.3 & $\$ 258$ & $\$ 1810$ \\
\hline Hospital & $\$ 4016568$ & 25.5 & $\$ 121$ & $\$ 849$ \\
\hline Ambulatory* & $\$ 2060234$ & 13.1 & $\$ 62$ & $\$ 435$ \\
\hline Nursing home care & $\$ 1267232$ & 8.0 & $\$ 38$ & $\$ 268$ \\
\hline Prescriptions & $\$ 1133432$ & 7.2 & $\$ 34$ & $\$ 240$ \\
\hline Home health & $\$ 87157$ & 0.6 & $\$ 3$ & $\$ 18$ \\
\hline Indirect lost productivity & $\$ 7195156$ & 45.7 & $\$ 217$ & $\$ 1521$ \\
\hline Illness & $\$ 1512210$ & 9.6 & $\$ 46$ & $\$ 320$ \\
\hline Premature death $\dagger$ & $\$ 5682946$ & 36.1 & $\$ 171$ & $\$ 1201$ \\
\hline Men, Total & $\$ 9418889$ & 100.0 & $\$ 568$ & $\$ 3409$ \\
\hline Direct cost & $\$ 4243211$ & 45.1 & $\$ 256$ & $\$ 1536$ \\
\hline Hospital & $\$ 2130101$ & 22.6 & $\$ 128$ & $\$ 771$ \\
\hline Ambulatory* & $\$ 1076995$ & 11.4 & $\$ 65$ & $\$ 390$ \\
\hline Nursing home care & $\$ 472147$ & 5.0 & $\$ 28$ & $\$ 171$ \\
\hline Prescriptions & $\$ 538307$ & 5.7 & $\$ 32$ & $\$ 195$ \\
\hline Home health & $\$ 25661$ & 0.3 & $\$ 2$ & $\$ 9$ \\
\hline Indirect lost productivity & $\$ 5175678$ & 54.9 & $\$ 312$ & $\$ 1873$ \\
\hline Illness & $\$ 762098$ & 8.1 & $\$ 46$ & $\$ 276$ \\
\hline Premature death $†$ & $\$ 4413579$ & 46.9 & $\$ 266$ & $\$ 1598$ \\
\hline Women, total & $\$ 6340890$ & 100.0 & $\$ 383$ & $\$ 3221$ \\
\hline Direct cost & $\$ 4321412$ & 68.2 & $\$ 261$ & $\$ 2195$ \\
\hline Hospital & $\$ 1886467$ & 29.8 & $\$ 114$ & $\$ 958$ \\
\hline Ambulatory* & $\$ 983239$ & 15.5 & $\$ 59$ & $\$ 499$ \\
\hline Nursing home care & $\$ 795085$ & 12.5 & $\$ 48$ & $\$ 404$ \\
\hline Prescriptions & $\$ 595125$ & 9.4 & $\$ 36$ & $\$ 302$ \\
\hline Home health & $\$ 61496$ & 1.0 & $\$ 4$ & $\$ 31$ \\
\hline Indirect lost productivity & $\$ 2019478$ & 31.8 & $\$ 122$ & $\$ 1026$ \\
\hline Illness & $\$ 750111$ & 11.8 & $\$ 45$ & $\$ 381$ \\
\hline Premature death $\dagger$ & $\$ 1269367$ & 20.0 & $\$ 77$ & $\$ 645$ \\
\hline
\end{tabular}


Table 3 Smoking cost studies by type of study, California

\begin{tabular}{|c|c|c|c|c|}
\hline \multirow[b]{2}{*}{ Study } & \multirow[b]{2}{*}{ Study year } & \multicolumn{3}{|c|}{ Cost (billions) } \\
\hline & & Direct & Indirect & Total \\
\hline Kaplan and Wright ${ }^{28}$ & 1985 & $\$ 4.8$ & $\$ 2.3$ & $\$ 7.1$ \\
\hline US DHHS ${ }^{29}$ & 1985 & NA & NA & $\$ 5.8$ \\
\hline California Dept of Health Services ${ }^{30}$ & 1988 & NA & NA & $\$ 5.9$ \\
\hline Rice and $\mathrm{Max}^{31}$ & 1989 & $\$ 2.4$ & $\$ 5.2^{*}$ & $\$ 7.6$ \\
\hline Max and Rice ${ }^{32}$ & 1993 & $\$ 3.6$ & $\$ 6.3^{*}$ & $\$ 10$ \\
\hline V Miller et $a^{\beta 4}$ & 1993 & $\$ 7.1$ & NA & NA \\
\hline L. Miller et $a l^{16}$ & 1993 & $\$ 8.7$ & NA & NA \\
\hline $\mathrm{CDC}^{33}$ & 1998 & $\$ 7.1$ & NA & NA \\
\hline Current study & 1999 & $\$ 8.6$ & $\$ 7.2 \dagger$ & $\$ 15.8$ \\
\hline \multicolumn{5}{|c|}{$\begin{array}{l}\text { *Discounted at } 4 \% \text {. } \\
\text { tDiscounted at } 3 \% \text {. } \\
\text { CDC, Centers for Disease Control and Prevention; DHSS, Department of Health and Human Services; NA, not } \\
\text { available }\end{array}$} \\
\hline
\end{tabular}

of smoking cost Californians $\$ 15.8$ billion in 1999. These estimates are conservative for several reasons. We did not take into account costs due to passive smoking, fires caused by cigarettes, non-health sector costs such as transportation to providers, and costs of smoking cessation programmes and other interventions to control smoking. We used the human capital approach in this study rather than contingent valuation, ${ }^{27}$ which would yield much higher estimates for values of life.

We used average earnings in our estimates of lost productivity. We acknowledge that smokers tend to have lower than average earnings, but earnings data are not available for California smokers. Had these data been available, our estimates of indirect costs would likely have been slightly lower.

Our estimates of the cost of smoking in California are not the first; table 3 summarises the previous cost estimates made for the state. Studies that included both direct and indirect costs reported totals ranging from $\$ 5.8$ billion for 1985 to $\$ 10$ billion for $1993 .{ }^{28-32}$ Our estimates of total costs for 1999 amount to $\$ 15.8$ billion. Our estimate of direct smoking costs amounted to $\$ 8.7$ billion which is almost three times the estimate made for $1989^{31}$ and twice that made for 1993. ${ }^{32}$ These differences result from the use of different methodology and data sources. The first five studies estimate SAFs using the epidemiological approach for attributable risk. Relative risks for mortality or for healthcare utilisation were used as a proxy for the relative risk of health expenditures. The SAFs in the current study were estimated using models which directly related smoking to health expenditures while controlling for other confounding factors, thus estimating the SAFs directly.

The three other recent studies also used econometric models and produced higher direct cost estimates than the earlier studies. The Centers for Disease Control and Prevention (CDC) study ${ }^{33}$ estimated a direct cost of $\$ 7.1$ billion for 1998, a $21 \%$ difference from ours. Part of the

\section{What this paper adds}

Much of the research on smoking related costs has been conducted at the national level or did not use the most current accepted methodology for cost estimation. Few studies have developed current estimates at the state or local level; yet this is where many tobacco control activities occur.

This study shows the feasibility of applying the econometric approaches used at the national level to obtain good state estimates. The modelling approach is described and the most current estimates for California are presented. difference can be attributed to the annual cost increase; the remainder is the difference in methodology. The CDC estimates were based on the published SAF estimates by V Miller and colleagues, ${ }^{34}$ in which health expenditures were modelled with a reduced form model. Our study was based on a causal relationship framework developed by L Miller and colleagues, ${ }^{16}$ which we believe yields more accurate estimates. The V Miller and L Miller models are compared in detail elsewhere. ${ }^{35}$

Different from L Miller, ${ }^{16}$ the current study used more recent data sources. Also, we included only the "biological effect" in the calculation of SAFs while Miller included both the "biological $t$ " and the "mixed effect". Because $80-90 \%$ of the total effect came from the biological component and the biological SAFs were more stable, this refinement improves the methodology. Despite the fact that personal medical care expenditures have increased since 1993, the lower SAFs resulted in our direct cost estimate for 1998 being $\$ 8.6$ billion compared to $\$ 8.7$ billion for 1993 by L Miller. ${ }^{16}$

Californians not only have lower smoking prevalence than most other states, but current California smokers have lower per capita consumption. This might cause our modelling approach to overestimate costs. However, the needed data on smoking intensity over time were not available to permit a model of the impact of this effect on health expenditures.

Between 1989 and 1999, the first decade of the California Tobacco Control Program, adult smoking prevalence decreased $24 \%$ in California compared to $17 \%$ in the USA as a whole. ${ }^{36}$ It is clear from this and our previous work that there has not been a dramatic reduction in smoking-related costs in the state over this time period. Without the tobacco control programme, smoking related costs would have been even higher. Thus, even a state such as California, with a tobacco control programme that is considered among the strongest in the nation, must remain vigilant in its efforts to maintain hard won reductions in smoking prevalence, and cannot expect cost savings to show up for a number of years.

The question has been raised as to whether smokers are paying for their smoking habits. A related question is whether cigarette taxes are at the appropriate level. From an economic perspective, the tax should be set to cover the external costs of smoking-that is, the costs imposed by smokers on others. While we did not estimate the proportion of costs that are internal versus external, Gruber ${ }^{37}$ summarised other studies which found that external health care costs alone probably range from $\$ 1.55$ to $\$ 1.85$ per pack. In addition, sizeable external losses in workplace productivity have not been estimated. ${ }^{37}$ We found that smoking related direct costs per pack of cigarettes were $\$ 6.16$, and total direct and indirect costs totalled $\$ 11.34$ per pack. Current tax proposals in California are to raise the tax per pack of 
cigarettes by up to $\$ 1.50$, which would seem easily justified by the likely magnitude of the external costs. However, it must also be noted that from an equity perspective, if part of the tobacco tax increase is to be passed on to smokers, the revenues raised should be used to help them quit smoking and obtain health care for smoking related illnesses they may already have.

The public health impact of cigarette smoking in California and in the USA is enormous in terms of the large number of preventable illnesses, premature deaths, and high health care costs and productivity losses. Policymakers must continue to push legislation and ordinances that encourage people to quit or to never take up smoking. The approach presented here is useful for other states, nations, and jurisdictions interested in estimating the costs of smoking.

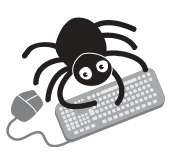

To view the Methods section, visit the Tobacco Control website-http://www.tobaccocontrol.com/ supplemental.

\section{Authors' affiliations}

W Max, D P Rice, H-Y Sung, Institute for Health \& Aging, University of California, San Francisco, San Francisco, California, USA

X Zhang, Institute of Social Development and Public Policy, Beijing Normal University, Beiijing, China

L Miller, School of Social Welfare, University of California, Berkeley, Berkeley, California, USA

\section{REFERENCES}

1 McGinnis JM, Foege WH. Actual causes of death in the United States. JAMA 1993:270:2207-12.

2 Fellows JL, Trosclair MS, Adams EK, et al. Annual smoking-attributable mortality, years of potential life lost, and economic costs - United States, 1995-999. MMWR Morb Mortal Wkly Rep 2002;51:300-3.

3 US Department of Health, Education, and Welfare. Smoking and health. Report of the Advisory Committee to the Surgeon General of the Public Health Service. Washington, DC: Public Health Service, 1964, (PHS Publication No.1103.).

4 US Department of Health and Human Services. The health consequences of smoking: cancer. A report of the Surgeon General, 1982. Bethesda, Maryland: Public Health Service, Office on Smoking and Health, 1982 (DHHS Publication No (PHS) 82-50179.)

5 US Department of Health and Human Services. The health consequences of smoking: cardiovascular disease. A report of the Surgeon General, 1983. Rockville, Maryland: Public Health Service, Office on Smoking and Health, 1983, (DHHS Publication No (PHS) 84-50204.).

6 US Department of Health and Human Services. The health consequences of smoking: chronic obstructive lung disease. A report of the Surgeon General, 1984. Rockville, Maryland: Public Health Service, Office on Smoking and Health, 1984, (DHHS Publication No (PHS) 84-50205.).

7 US Department of Health and Human Services. Reducing the health consequences of smoking: 25 years of progress. A report of the Surgeon General, 1989. Rockville, Maryland: Public Health Service, Centers for Disease Control, Office on Smoking and Health, 1989, (DHHS Publication No (CDC) 89-8411.).

8 US Department of Health and Human Services. Preventing tobacco use among young people. A report of the Surgeon General, 1994. Atlanta, Georgia: Public Health Service, Centers for Disease Control and Prevention, Office on Smoking and Health, 1994, (US Government Printing Office Publication No S/N 017-001-00491-0.).

9 US Department of Health and Human Services. Tobacco use among U.S racial/ethnic minority groups: African Americans, American Indians and Alaska Natives, Asian Americans and Pacific Islanders, Hispanics. A report of the Surgeon General, 1998. Atlanta, Georgia: Centers for Disease Control and Prevention, Office on Smoking and Health, 1998, (US Government Printing Office Publication No S/N 017-001-00527-4.).

10 US Department of Health and Human Services. Women and smoking: A report of the Surgeon General. Atlanta, Georgia: US Department of Health and Human Services, Centers for Disease Control and Prevention, 2001.

11 Centers for Disease Control, Prevention (CDC). State-specific prevalence of current cigarette smoking among adults-United States, 2002. MMWR Morb Mortal Wkly Rep 2004;52:1277-80.

12 Tobacco Education and Research Oversight Committee. Toward a tobacco free California, 2003-2005: the myth of victory. Sacramento, California: California Department of Health Services, January, 2003.

13 Max W, Rice DP, Zhang X, et al. The cost of smoking in California, 1999. Sacramento: California Department of Health Services, 2002, Available at http://repositories.cdlib.org/ctcre/tcpmus/CA2002.

14 Bartlett JC, Miller LS, Rice DP, et al. Medical expenditures attributable to cigarette smoking-United States, 1993. MMWR Morb Mortal Wkly Rep 1994;43:469-72

15 Miller LS, Zhang X, Rice DP, et al. State estimates of total medical expenditures attributable to cigarette smoking, 1993. Public Health Reports 1998;113:447-58

16 Miller LS, Zhang X, Novotny T, et al. State estimates of Medicaid expenditures attributable to cigarette smoking, fiscal year 1993. Public Health Reports 1998;113:140-1.

17 Zhang X, Miller LS, Max W, et al. Cost of smoking to the Medicare program, 1993. Health Care Financing Review 1999;20(4):179-96.

18 Zhang X. Cigarette smoking and nursing home utilization in the United States: An estimate of 1993 national and state nursing home expenditures attributable to cigarette smoking. Berkeley: PhD Dissertation, University of California, 1999.

19 Martin AB, Whittle LS, Levit KR. Trends in state health care expenditures and funding: 1990-1998. Health Care Financing Review 2001;22(4):111-40.

20 Lilienfeld AM, Lilienfeld DE. Foundations of epidemiology. Oxford: Oxford University Press, 1980

21 US Bureau of the Census. In: Statistical abstract of the United States: 2000 120th ed. Washington DC: US Government Printing Office, 2000.

22 Douglass JB, Kenney GM, Miller TR. Which estimates of household production are best? Journal of Forensic Economics 1990;4:25-45.

23 California Department of Health Services (CDHS). California death statistical master file-1999. Sacramento: CDHS, Center for Health Statistics, Office of Health Information and Research, Vital Statistics Section, 1999.

24 California Department of Health Services (CDHS). Abridged life table for total population, 1999. Sacramento: CDHS, Center for Health Statistics, Office of Health Information and Research, Vital Statistics Section, 1999.

25 Max W, Rice DP, Sung H-Y, et al. Valuing human life: estimating the present value of lifetime earnings, 2000. Available at: http://repositories.cdlib.org/ ctcre/esarm/PVLE2000.

26 National Cancer Institute (NCI). Health effects of exposure to environmental tobacco smoke: the report of the California environmental protection agency, Smoking and Tobacco Control Monograph no. 10. Bethesda, Maryland: US Department of Health and Human Services, National Institutes of Health, National Cancer Institute, 1999, (NIH Publication No 99-4645.).

27 Institute of Medicine. Hidden costs, value lost: uninsurance in America. Washington DC: The National Academies Press, 2003:35.

28 Kaplan GA, Wright WE. Health and economic impact of smoking, California, 1985. Sacramento: California Department of Health Services, 1988.

29 US Department of Health and Human Services. Smoking and health, a national status report: A report to Congress, 2 nd ed.revised February 1990. Rockville, Maryland: US Public Health Service, 1990, (DHHS Publication No (CDC) 87-8396.).

30 California Department of Health Services (CDHS). Health and economic impact of smoking: California, 1988, Technical Report No.5. Sacramento: California Chronic and Sentinel Diseases Surveillance Program, 1992.

31 Rice DP, Max W. The cost of smoking in CA, 1989. Sacramento: California Department of Health Services, 1992.

32 Max W, Rice DP. The cost of smoking in California, 1993. Tobacco Control Summer 1995;4(suppl 1):S39-46.

33 Centers for Disease Control, Prevention (CDC). Tobacco control state highlights 2002: impact and opportunity. Atlanta, Georgia: Department of Health and Human Services, CDC, National Center for Chronic Disease Prevention and Health Promotion, Office on Smoking and Health, 2002, Available at:http://www.cdc.gov/tobacco/statehi/statehi_2002.htm.

34 Miller VP, Ernst C, Collin F. Smoking-attributable medical care costs in the USA. Soc Sci Med 1999:48:375-91.

35 Warner KE, Hodgson TA, Carroll CE. Medical costs of smoking in the United States: estimates, their validity, and their implications. Tobacco Control 1999;8:290-300

36 Gilpin EA, Emery SL, Farkas AJ, et al. The California tobacco control program: a decade of progress, results from the California tobacco surveys, 1990-1999. La Jolla: University of California, San Diego, 2001

37 Gruber J. The economics of tobacco regulation. Health Affairs 2002;21(2):146-62. 